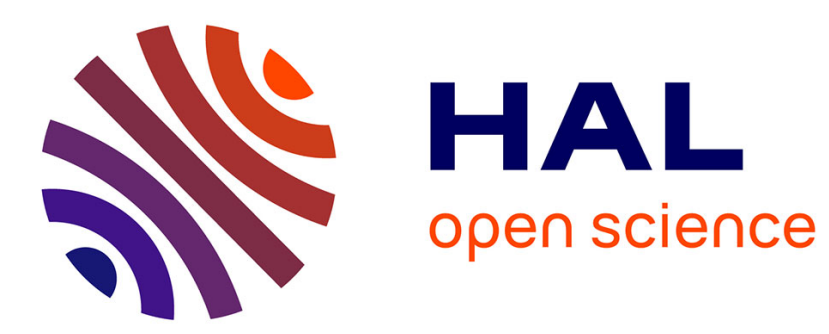

\title{
Effect of congruent scent diffusion on individual creative fluidity: Mental imagery instruction and iconic stimulus as possible moderators
}

Laurent Busca, Julien Grobert, Cyrielle Vellera

\section{- To cite this version:}

Laurent Busca, Julien Grobert, Cyrielle Vellera. Effect of congruent scent diffusion on individual creative fluidity: Mental imagery instruction and iconic stimulus as possible moderators. Creativity and Innovation Management, 2021, 30 (3), pp.511-522. 10.1111/caim.12443 . hal-03256558

\section{HAL Id: hal-03256558 \\ https://hal.umontpellier.fr/hal-03256558}

Submitted on 10 Jun 2021

HAL is a multi-disciplinary open access archive for the deposit and dissemination of scientific research documents, whether they are published or not. The documents may come from teaching and research institutions in France or abroad, or from public or private research centers.
L'archive ouverte pluridisciplinaire HAL, est destinée au dépôt et à la diffusion de documents scientifiques de niveau recherche, publiés ou non, émanant des établissements d'enseignement et de recherche français ou étrangers, des laboratoires publics ou privés. 


\title{
Effect of congruent scent diffusion on individual creative fluidity: mental imagery instruction and iconic stimulus as possible moderators
}

\author{
Laurent Busca \\ Université de Montpellier, MRM \\ laurent.busca@umontpellier.fr \\ Julien Grobert \\ Toulouse School of Management, Université Toulouse Capitole, TSM Research \\ julien.grobert@tsm-education.fr \\ Cyrielle Vellera \\ Toulouse School of Management, Université Toulouse Capitole, TSM Research \\ cyrielle.vellera@tsm-education.fr
}

\begin{abstract}
This research explores the joint role of a diffusion of a scent congruent with the proposed product and two types of stimulation (instruction to imagine mentally and iconic stimulus) in order to improve the resulting individual creativity (in terms of fluidity or quantity of ideas generated). Through two experiments performed on 126 and 442 respondents, respectively, our results highlight the following: (1) The direct and positive effect of a diffusion of a scent congruent with the proposed product on the number of ideas generated. We find no support of mental imagery formation simplicity as a mediator of this relation; (2) The use of a mental imagery instruction reinforces the impact of a congruent scent on the number of ideas generated, whereas a pictorial stimulus does not play a moderating role in the relationship. The two types of stimuli therefore do not produce the same effects. The implications and managerial perspectives, limits and avenues for future research are further discussed.
\end{abstract}

Keywords: creative fluidity; olfactory stimulation; scent; congruence; mental imagery; mental imagery instruction; pictorial/iconic stimulus; sensory marketing

This article has been accepted for publication in Creativity and Innovation Management. Please quote it with its original reference:

Busca, L., Grobert, j., \& Vellera, C. (2021), Effect of congruent scent diffusion on individual creative fluidity: mental imagery instruction and iconic stimulus as possible moderators, Creativity and Innovation Management, Online First. https://doi.org/10.1111/caim.12443 


\section{Effect of congruent scent diffusion on individual creative fluidity: mental imagery instruction and iconic stimulus as possible moderators}

\section{Introduction}

For a long time, co-creation remained the business of a few informed users with strong innovative potential, such as lead users (Lilien et al., 2002), emerging nature consumers (Hoffman et al., 2010) or creative profiles (Berthon et al., 2007). Nevertheless, identification of these groups is a difficult process (due to their low proportion in the population). Facing a strong pressure to innovate constantly, practitioners have extended co-creation approaches to all users (current or potential), i.e., the general public (or crowd). Consequently, how to stimulate the creative performance of these increasingly "varied profiles of participants" (Le Nagard and Reniou, 2013, p. 61) involved in idea production sequences is of critical importance. From this perspective, the scientific literature points out that it is possible to stimulate individuals to act positively on their creative potential and creative activity skills (Basadur et al., 1982; Gordon, 1968; Osborn, 1963) in various ways such as the use of creative idea production training or creative imagery, essentially based on visualization (Scott et al., 2004a\&b; Burroughs et al., 2011).

At a time when sensory experiences are increasingly at the heart of the concerns of marketers (Rieunier et al, 2017), few works report links between creativity and sensory factors (Ritter and Ferguson, 2017) on the one hand, and between sensory factors and mental imagery (Cornil and Chandon, 2016; Krishna and Elder, 2011) on the other; nevertheless, mental imagery has proven an interesting concept for the study of creative processes (Dahl et al., 1999, Vellera and GavardPerret, 2016a\&b).

The use of imaging instructions [1] or iconic stimuli [2] to increase the probability of internal mental imaging activity constitute direct solicitations of the mental structures involved in information processing, whereas the effect of olfactory stimuli appears to be a stimulation of a more unconscious order (Lenclud, 2006). Mental imagery refers to "(a) any quasi-sensory or quasiperceptive experience, (b) of which we may be aware, (c) which develops in the absence of the stimulation conditions known to produce its authentic sensory or perceptive correspondent, (d) which can be expected to have effects different from those of its sensory or perceptive correspondent" (Richardson, 1969, p. 2). Thus, the conjunction of imaging instructions and olfactory stimulation could enable the triggering of both conscious and unconscious processes, both of which are recognized as being involved in creativity (Ritter and Dijksterhuis, 2014).

The aim of this exploratory research is to understand which stimuli to use to foster creativity, seen from the angle of its fluidity (quantity or number of ideas/outputs generated), in order to identify how to use them to improve the creative performance of individuals. We focus on creative fluidity, the quantitative dimension of creativity (Fernández-Abascal et Martín Díaz, 2013), for two main reasons. First, from a theoretical standpoint, creative problem solving can be seen as an "interplay of divergent (ideation) and convergent (evaluative and integrative) modes of thought" (Forthmann et al., 2016). Divergent thinking, which relates on subjects' ability to search many ideas in various directions -in other words, to think fluently- has been widely documented in the literature as an indicator of creative potential and creative thought (Guilford, 1950; Torrance, 1976; Runco, 1991; 
Runco \& Acar, 2012). In line with this approach, the probability of finding a new and adapted idea is increased as reported by Guilford (Guilford, 1950: 452): "the person who is capable of producing a large number of ideas [...] has a greater chance of having significant ideas". At this stage of the ideation process, quantity of ideas is therefore advisable to generate and explore many possible solutions in a "free-flowing" and non-linear manner in order to gain insights about the problem to solve.

Second, from a managerial point of view, creativity judgements cannot take into account a very important managerial element: the fit between an idea and the production capabilities of a particular firm. Product managers are the most relevant judges of an idea when it comes to implementing it in their company. While other managers or experts can evaluate the absolute usefulness of the idea, they obviously cannot incorporate the needs of a specific firm inside their judgement. For these reasons, maximizing creative fluidity seems to be the most practically adequate output for a manager: with a sufficient amount of ideas, product managers will have increased probabilities to identify valuable creative propositions while being the most relevant judges for their fit with the production capabilities and strategic imperatives of their firm.

Hence, the objectives of this work are multiple: (1) to improve knowledge of the direct effect of scent diffusion on the creative fluidity of individuals; (2) to contribute to the study of the cognitive mechanisms and processes involved in certain dimensions of creativity by studying the role of mental imagery as an underlying mechanism in the exercise of creativity and (3) to analyze the moderating role of mental imagery activity stimuli (imagery instruction and iconic stimulus) on the link between congruent scent diffusion and individual creative fluidity.

Through two experiments carried out on 126 and 442 subjects, respectively, our results highlight: (1) The direct and positive effect of a diffusion of a scent congruent with the proposed product on the number of ideas generated. We find no support of mental imagery formation simplicity as a mediator of this relation; (2) The use of a mental imagery instruction reinforces the impact of a congruent scent on the number of ideas generated, whereas a pictorial stimulus does not play a moderating role in the relationship. The two types of stimuli therefore do not produce the same effects. These results are discussed below.

\section{Literature Review}

The influence of sensory stimuli on the creativity of individuals is an emerging field of research, the majority of which has focused on sight to the detriment of the other senses (Zhu and Mehta, 2017). Today, however, there is a growing body of research that focuses on the sensory perception of individuals and the fact that our sensory perceptions could guide our thinking, according to the principles of embodied cognition (Krishna et al., 2017). Indeed, recent research shows that individuals' senses can sometimes change their perceptions with underlying processes that need to be better understood (Lee, 2016) and that have an impact on judgments and decision-making (Lee and Schwartz, 2014). For example, depending on the brightness of a room, individuals would be more or less stimulated to innovate, and in particular, a dimmed light, by reducing the inhibition of individuals, would favor their creativity (innovative dimension of the ideas generated) (Wang et al., 2019). Similarly, touch would produce similar results regarding the creativity of individuals, 
who would tend to come up with more original and new ideas as a result of tactile manipulation (Kim and Krishnan, 2013). Following these initial results on two senses, the role of olfaction has been little investigated, despite the investigation of its effects in terms of memorization and emotional and cognitive inferences (Maille, 2001). Among the few studies on the link between smell and creativity, Knasko (1992) reports a weak link between the diffusion of a pleasant scent and individual creativity. Others have further investigated this link and shown the mediating role of positive emotions in the process: a pleasant scent provokes a positive emotion that promotes creativity (Baron and Thomley, 1994). Similarly, scents released during sleep may enhance individual creativity (Ritter et al., 2012). However, the relationship is partial, suggesting that other mechanisms mediate this effect, potentially linked to other dimensions of sensory stimuli.

Furthermore, an important dimension of sensory stimuli is the congruence between the manipulated stimuli and the creative task concerned. Maille and Fleck (2011, p.91) define congruence "as the fact that two entities go well together." In the field of sensory marketing, research shows that when two stimuli are congruent, the individual's sense of arousal is increased (Mattila and Wirtz, 2001), as are the inferences made between the two stimuli (Ardelet-Massieu et al., 2010). Some authors consider that there is a semantic connection between the scent and the field, the product or the other element the scent is in nexus with (Bosmans, 2006), this connection could be perceived as a kind of congruence between elements. Other authors are speaking about two theories of congruence (Errajaa et al., 2020): the theory of cognitive balance and the theory of processing fluency. The first theory posits that people try to find an equilibrium between two concepts or elements they are observing, there is a kind of "mental" balance to find. On the other hand, the second theory is about the facility of processing the information, the theory focuses on the process of treatment and not on the real fit between two elements. From the mental balance perspective, we can speculate that a congruent scent will provoke approach reactions; from the processing fluency perspective, we can argue that congruence will facilitate creative thinking process. Furthermore, the diffusion of a congruent scent not only facilitates but also stimulates cognitive processes, particularly in terms of search and acquisition of information but also in the search for variety (Mitchell et al., 1995). These elements lead us to the following hypothesis:

H1: The diffusion of a congruent scent ( $v s$. the absence of a scent) favors the creativity of individuals in terms of its fluidity (quantity or number of ideas generated).

Furthermore, sensory marketing research has highlighted a link between olfactory stimulation and mental imagery. In fact, the diffusion of scents has an impact on the resulting production of mental images (Leguerer, 1988; Nallet, 1985; Arshamian and Larsson, 2014; Herz and Schooler, 2002). A particular scent could lead an individual to think precisely about an object or situation. ArdeletMassieu (2011) reminds us that, in order for mental images to function in the best way possible, the scent must be congruent with the product, place or event being studied.

Mental imagery, a particular form of mental representation, is classically defined as "an experience that resembles a perceptual experience but occurs in the absence of the stimuli that trigger the corresponding perceptions" (Stanford Encyclopedia of Philosophy). Producing "effects that are different from those of its sensory or perceptual counterpart" (Richardson, 1969, p. 2), mental imagery plays "a major role in creative and inventive activities" (Denis, 1989, p. 254) because they "are easily altered, can represent multiple aspects of a problem, can be manipulated quickly, and do not have the well-defined limits of mental representations" (Kim, 1990, quoted by Lubart, 2003, 
p. 17). Indeed, beyond the stories and reports of historically famous people who attribute a potentially influential role in their creative activities to mental imagery (Shepard, 1978), a significant amount of psychological research has emerged, based on two main approaches (LeBoutillier and Marks, 2003): (1) the individual differences approach seeks to identify possible empirical links between measures of mental imagery and measures of creativity (via personality inventories, tests of divergent or creative thinking, in particular); (2) the second approach, the image-producing approach, is based on the principle that "every individual has the potential to make creative discoveries in his or her imagery" (Finke, 1990, p.1). This approach centers on creative invention through the visualization of thought. Experimental research in this area involves encouraging subjects to assemble different basic elements and parts through the use of mental images (visual synthesis of artificial forms) in order to create new emerging objects and forms. This stream of psychological research has paved the way for some consideration of the mental imagery/creativity relationship in the management discipline. In particular, Dahl et al. (1999) were interested in the effects of mental imagery on the conception (design) of new products initiated by designers by highlighting the effects of the type of visual mental imagery solicited (imagination imagery) and its content (customer incorporation in the visualization). More recently, Vellera and Gavard-Perret (2016b) have shown that it is possible to act, by means of instructions (in relation to a control situation), on imaging processes that are suspected of being involved in creative processes to improve the resulting creativity. These results highlight mental imagery as an underlying mechanism that explains creative processes.

As a multisensory concept, mental imagery is available in all of the modalities of perception (Finke, 1985): visual, auditory, olfactory, gustatory, kinesthetic or sensory-motor and somatosensory or organic. According to Gavard-Perret and Helme-Guizon (2003, p. 63), "a (multisensory) mental imagery activity can be triggered by a stimulus perceived in a (single) sensory modality," as in the famous Proustian story ("A la recherche du temps perdu", Marcel Proust, 1871-1922) where the simple scent of madeleines suddenly plunges the writer into an uplifting of memories of childhood, full of emotions and rich in meaning. To illustrate this hypothesis, Gavard-Perret and HelmeGuizon (2003) use examples illustrating the ability of external sensory stimuli to act on subsequent internal mental imagery. For instance, the audience of a TV ad for a car can "see" themselves driving the car and "feel" specific multi-sensory sensations related to a driving experience. Additionally, an individual, subjected to the noise of a lawnmower, is able to imagine the scene visually and the scents and tactile sensations associated with mowing a lawn (Miller and Marks, 1982). Furthermore, an individual exposed to an advertisement for a brand of coffee, including a visual representing a coffee-tasting scene, will be able to perceive images of sensory registers other than visual ones, such as scents and/or taste sensations (Helme-Guizon, 1997). These elements show that the use of sensory stimuli is likely to play a facilitating role in triggering mental imagery activity. Consequently, and insofar as we have previously discussed the possible involvement of mental imagery in creative processes, it is suggested that the mental imagery formation simplicity [3] mediates the degree of accessibility with which a stimulus activates information stored in longterm memory (Denis, 1989; Kisiekius and Sternthal, 1984) on the effects of a congruent olfactory stimulation on creative fluidity. Hence, the second hypothesis is as follows:

H2. The effect of the diffusion of a scent congruent with the creative task ( $v s$. absence of a scent) on creative fluidity is mediated by the mental imagery formation simplicity. 
To understand the effects of congruent scents on mental imagery and improve the resulting creative fluidity, it is important to examine whether particular types of stimulation of mental imagery activity should be favored, in conjunction with congruent scents diffusion, to have a positive impact on the production of creative ideas. Since the perception of a scent causes cognitive and emotional effects beyond the control of reason (Maille, 2001), it may be possible that the joint activation of a task-focused creativity process could maximize the influence of the congruent scent by directing the inferences caused by the scent to the context of the creative task. Mental imagery stimulations are capable of fulfilling this function. Indeed, it is possible to elicit and manipulate mental imagery by acting on the process, particularly through appropriate stimuli. The literature distinguishes several types of external stimuli (Lutz and Lutz, 1978), including iconic stimuli (images, drawings, illustrations, etc.) and imagery instructions. This last form of stimulation refers to direct and intentional instructions related to the concept in question made up of several verbal stimuli such as groupings of words, sentences or texts. The superiority of using instructions to provoke a mental imagery has been demonstrated in advertising communication, innovation evaluation and creative contexts (Denis, 1982; Bone and Ellen, 1990, 1992; Dahl et al., 1999; Dahl and Hoeffler, 2004; Gregory et al., 1982).

In their work, Dahl et al. (1999) highlight that prior to a design task, the combination of an imagination imagery stimulation and an instruction asking the target customers to picture themselves in the same imagery lead to significantly more original, useful, and attractive designer products. Vellera and Gavard-Perret (2016b) examined the effect of two types of stimulation on imaging activity (prior instruction and training in mental imagery given before a creative task) and revealed favorable effects of these stimuli, particularly on the quantity of ideas produced. Hence the instruction concerning mental imagery could have an impact on the production of ideas. The use of another sensory stimulus (scent) could may be facilitate the process of thinking and by consequence, lead people to have more ideas and with a better creative fluidity. More specifically, the more rapid the olfactory perception is, the less subject to reason control than other sensory perceptions (Maille, 2001): it would therefore be able to produce varied mental images that would then be refocused on the context of the creative task through mental imagery instruction. This leads us to the following hypothesis:

H3a: The presence of mental imagery instruction ( $v s$. absence of instruction) positively moderates the link between congruent scent diffusion and creative fluidity.

Many studies show the impact of a visual stimulus on individual creativity (Jaquish, 1983). A recent research found that pictorial stimuli increase the provocation of ideas (in term of rarity and nonobviousness) (Borgianni et al., 2020). Pictures could also facilitate the production of ideas by helping people focus on the thematic of innovation and by leading people to think about the domain of the task (Brun, Le Masson and Weil, 2019). The use of pictures can influence the thinking pattern of people, a kind of priming can appear (even between two distant concept) and therefore pictures could modify the knowledge field and could lead to more original ideas (Brun, Le Masson and Weil, 2019). The strength of representation of a concept by a picture could also facilitate the creative process (Kristensen, 2004).

Studies show that multiple sensory stimuli (perfume and music) are thought to have an effect on an individual's cognitive abilities, particularly on repeated mental simulation (rumination) (Bonnin and Goudey, 2013) and on the way that individuals perceive their environment (Nenkov et al., 
2019). Finally, joint stimuli, by increasing the individual's arousal, can also lead to more precise and important inferences with respect to the initial concept to which they relate (Ardelet Massieu et al., 2010). However, a certain level of interstimuli congruence must also be achieved so that the signals are not contradictory. Thus, a strong sensory stimulation (cross-modal effect) could play a role in the performance of the individual depending on his level of attention (Spence, 2018). In line with the congruency concept, scents will also initiate specific thoughts, linked to the individual's culture, which will facilitate the process of semantic processing of the associations made (Nehmé et al., 2016). Fragrances can also be unconsciously related to concepts such as temperature (Madzharov, Block, \& Morrin, 2015) or gender (Krishna, Elder, \& Caldara, 2010), so the act of diffusing scents can trigger specific thoughts allowing to create precise inferences between different stimuli. Therefore, we propose that the combined presence of a congruent scent and a pictorial stimulus will provide an environment enhancing the creative fluidity of individuals. This leads to the following hypothesis:

H3b: The presence of a pictorial stimulus (vs. absence of an external pictorial stimulus) positively moderates the link between congruent scent diffusion and creative fluidity.

\section{Methodology and results}

The empirical approach adopted revolves around two experimental studies: the first aims to test the $\mathrm{H} 1$ and $\mathrm{H} 2$ hypotheses of the direct and mediated effect, through the mental imagery formation simplicity, of congruent scent on creative fluidity. The second experiment aims to test hypothesis $\mathrm{H} 3$ ( $\mathrm{a}$ and $\mathrm{b}$ ) relating to the conjunction of different forms of external stimulation of mental imagery activity (imagery instruction and pictorial stimulus).

\section{Study 1}

\section{Protocol and measures}

In a first experiment, subjects were recruited via quota-based (age and gender) convenience sampling in the context of a research methodology course. 23 students participating to this course were asked to recruit 6 participants each ( 3 male and 3 female, aged over 18), leading to 138 completed questionnaires. Respondents participated voluntarily in the study. Students acted as researchers and were given a strict procedure: respondents were to be completing the task at home, in a quiet room, alone with the experimenter, without food or hot drinks nearby (to avoid parasite scents). Specific consigns were given concerning spreading of scent (2 sprays of perfume for a normal room, e.g. 10 square meters) before the arrival of the respondent. Furthermore, they had to control the level of fragrance between each respondent and to ventilate the room for a better control of the level of the fragrance. Students did not know our research hypotheses; they just were aware of the global topic of the research. Respondents were first asked to come up with original ideas for an electric toothbrush (creative task borrowed from Gavard-Perret and Vellera, 2017, see appendix 1) involving but not limited to design, functionalities, technological or ergonomic improvements. Respondents were instructed to come up with as many innovative ideas as they could, without any time limit. Ideas were to be formulated using text, and respondents were told to include drawings if needed. 
Subjects were randomly assigned to two experimental groups: group 1 subjects (78 respondents) had to perform the task in the presence of a scent congruent with the product, whereas group 2 subjects (60 respondents) were not exposed to any scent. The scent, selected with the help of a company specializing in olfactory marketing, was that of fresh mint (which is supposed to remind the subject of the scent of the toothpaste during teeth-brushing experience). It was diffused via perfume sprays by student experimenters in the room before the creative brief was read and remained during the idea research phase. After the ideation task, subjects completed a questionnaire to collect the other variables (see measurement instruments - appendix 2). A manipulation check ("When reading the creative brief and while searching for ideas, did you feel a particular scent?") was included. A chi-squared test between the two modalities of scent and the two modalities of the manipulation check variable led to significant results $\left(\mathrm{Chi}^{2}=53.77, \mathrm{p}<0.001\right)$, outlining the success of the experimental manipulation.

The creative fluidity measure results from a simple counting of the ideas proposed. Other variables were measures on a 7-points Likert scale. Mental imagery formation simplicity $(\mathrm{M}=5.08$; $\mathrm{sd}=$ 1.84) was measured using the Helme-Guizon (1997) scale. Several controls were included in the questionnaire: individual creativity $(\mathrm{M}=4.08$; $\mathrm{sd}=1.68)$ taken from Vellera and Gavard-Perret (2017), the perceived personal role $(\mathrm{M}=4.30$; $\mathrm{sd}=1.57)$ taken from Vellera and Gavard-Perret (2017) adapted to the creative context, and the gender of the subject. Research on gender differences in both creativity tests and creative accomplishments are divergent and scattered (Amabile,1983; Baer \& Kaufman, 2008; Pagnani 2011; Runco et al. 2010). Additionally, the impact of consumers' perception of personal role remains relatively unexplored, especially in the creativity area. Perceived personal role refers to how an individual perceives his ability to contribute to the cause or task they have to participate in. Robinson, Irmak and Jayachandran (2012), in a cause-related marketing context, explain that giving more choice has proven beneficial on support of CM campaigns by enhancing the perceived personal role of individuals in helping the cause and in influencing campaign. Finally, the individual creativity measure approximates $e x$ ante differences of individual creativity among our respondents.

From these 138 questionnaires, 12 displayed missing data from several variables (11 questionnaires for mental imagery fluency and 1 for individual creativity) and could not be included in the analysis. In the end, 74 usable questionnaires were collected for Condition 1 - "Presence of a scent" and 52 for Condition 2 - "Absence of a scent", for a total of 126 respondents $\left(46 \%\right.$ male, $\mathrm{M}_{\text {Age }}=$ $36.1, \mathrm{sd}=17.5)$. A total of 523 ideas were generated by all respondents $(\min =1, \mathrm{Q} 1=3$, median $=4, \mathrm{Q} 3=5, \max =11$ ). Due to the non-normality of the creative fluency variable, we display the median and $1^{\text {st }}$ and $3^{\text {rd }}$ quartiles instead of the mean and standard deviation.

\section{Analysis and results}

To manage the non-normality of the dependent variable (creative fluidity), all our variables were rank transformed, a simple procedure recommended by Iman and Conover (1979) and Conover (2012). Observations were ordered from the smallest (receiving rank 1) to the largest. Ties were resolved by assigning the average rank of all observations concerned. The results were analyzed using an Analysis of Covariance (ANCOVA), used to estimate the difference of means between two modalities of a qualitative variable and allowing the inclusion of covariates, and the mediating 
effect was analyzed using the Process Macro (Hayes, 2013). We report our results in Table 1. For ANCOVA results, we display the effect size coefficient (partial eta-squared) and its $p$-value. For the mediation model, we display the effect size coefficient (beta) with its standard error and the 95\% and $90 \%$ bootstrapped confidence intervals (Hayes, 2013). We display the rank transformed estimated marginal means of mental imagery formation simplicity and creative fluidity in Figure 1 .

Table 1 - Results of Study 1 (Independent variable: Congruent Scent vs. Absence of Scent)

\begin{tabular}{|c|c|c|c|c|}
\hline \multirow{2}{*}{$\begin{array}{l}\text { Dependent variable } \\
\begin{array}{l}\text { Independent } \\
\text { variables }\end{array}\end{array}$} & \multicolumn{2}{|c|}{$\begin{array}{c}\text { Mental imagery formation } \\
\text { simplicity }\end{array}$} & \multicolumn{2}{|c|}{ Creative fluidity } \\
\hline & $\begin{array}{l}\text { Partial eta- } \\
\text { squared }\end{array}$ & $\mathrm{p}$ & $\begin{array}{l}\text { Partial eta- } \\
\text { squared }\end{array}$ & $\mathrm{p}$ \\
\hline Scent & $0.008 \mathrm{~ns}$ & 0.327 & $0.041 * *$ & 0.025 \\
\hline Individual creativity & $0.089 * * *$ & 0.001 & $0.003 \mathrm{~ns}$. & 0.556 \\
\hline Perceived Role & $0.000 \mathrm{~ns}$ & 0.902 & $0.000 \mathrm{~ns}$ & 0.856 \\
\hline Gender & $0.000 \mathrm{~ns}$ & 0.955 & $0.049 * *$ & 0.014 \\
\hline $\begin{array}{l}\text { Mental imagery } \\
\text { fluency }\end{array}$ & & & $0.054 * *$ & 0.010 \\
\hline \multicolumn{2}{|c|}{ Mediation model } & $\begin{array}{l}\text { Indirect effect } \\
\quad \text { Beta (se) }\end{array}$ & $\begin{array}{c}\text { LLCI } \\
95 \%(90 \%)\end{array}$ & $\begin{array}{c}\text { ULCI } \\
95 \%(90 \%)\end{array}$ \\
\hline $\begin{array}{l}\text { Scent } \\
\Rightarrow>\text { Mental imagery fo } \\
\Rightarrow>\text { Creative fluidity }\end{array}$ & ion simplicity & $1.55 * *(1.79)$ & $-1.53(-0.93)$ & $5.58(5.002)$ \\
\hline
\end{tabular}

$* * * \mathrm{p}<0.01, * * \mathrm{p}<0.05, * \mathrm{p}<0.1$, ns. Non-significant

Our results show no effect of scent on mental imagery formation simplicity $\left(\right.$ MRank $_{\text {Absence }}=60.15$; MRank $\left._{\text {Congruent }}=66.41 ; p=0.327\right)$. In the same way, the mediating hypothesis of mental imagery formation simplicity between the scent and creative fluidity is not supported by our results (Beta = $1.55,90 \%$ CI $[-1.53 ; 5.58])$. However, we find a significant positive direct effect of scent on creative fluidity $\left(\right.$ MRank $_{\text {Absence }}=63.27 ;$ MRank $\left._{\text {Congruent }}=78.42 ; \mathrm{p}=0.025\right)$. Figure 1 display a graphical illustration of our results. 


\section{Figure 1 - Estimated Marginal Means of Mental Imagery Formation Simplicity and Creative Fluidity (Study 1)}

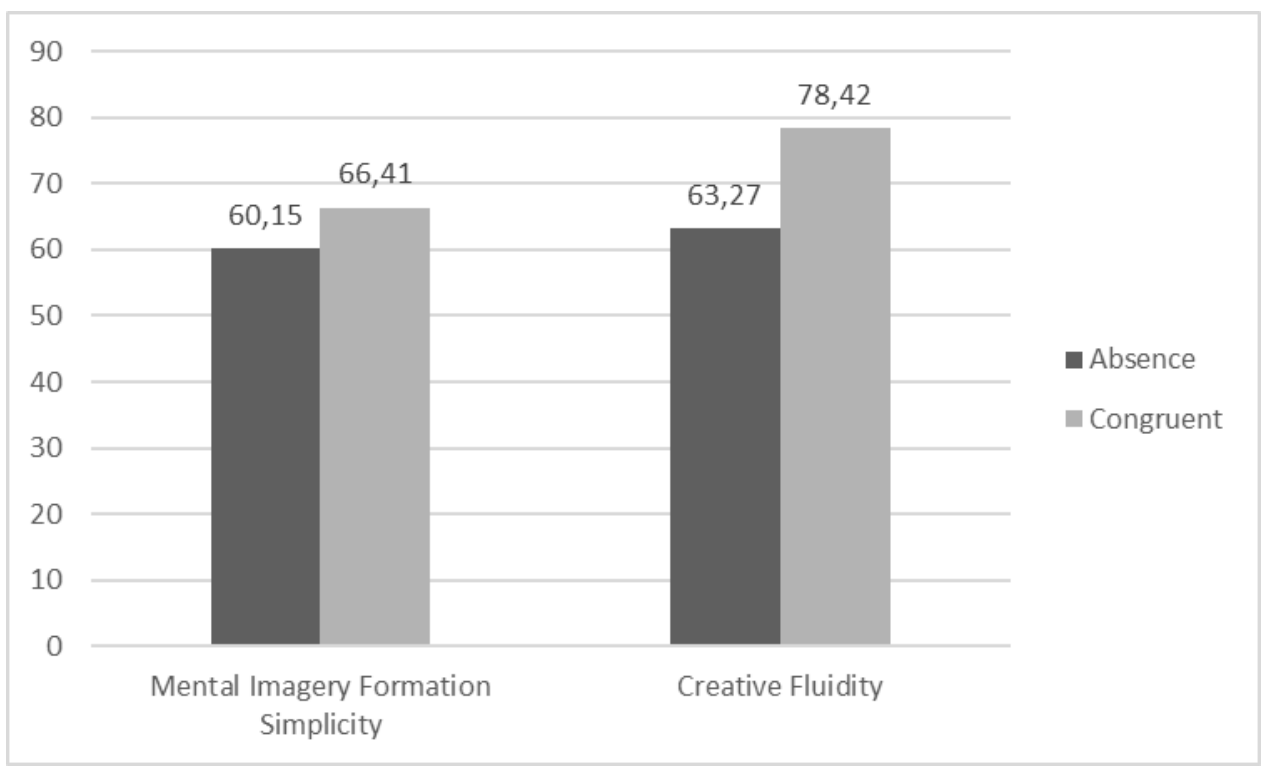

In terms of absolute number of ideas, a mean rank of 63.27 represents around 3.6 ideas, and a mean rank of 78.42 represents around 4.5 ideas. The diffusion of a congruent scent leads to an improvement of a bit less than 1 supplementary idea per participant. Finally, while the mediating effect of mental imagery formation simplicity is not supported, we find a direct effect of mental imagery formation simplicity (partial eta-squared $=0.054, \mathrm{p}=0.010$ ). Our results therefore support the influence of mental imagery mechanisms on creative fluency, but deny the ability of an olfactory stimulation to stimulate these mechanisms.

Our results support hypothesis $\mathrm{H} 1$ of a direct effect of a congruent scent on creative fluidity; however, hypothesis $\mathrm{H} 2$ of a mediating effect of mental imagery formation simplicity is not supported. The diffusion of a congruent scent thus leads to an improvement of creative fluidity, while not influencing mental imagery formation simplicity. As a results, with the influence of scent and mental imagery formation simplicity being independent, our second study investigates how the diffusion of scent interacts with other stimulations: a cognitive stimulation based on mental imagery (mental imagery instruction) and a sensorial stimulation (pictorial stimulation).

\section{Study 2}

\section{Protocol and measures}

In a second experiment, subjects were given the same creativity task as in Study 1, in the exact same conditions. Respondents were recruited via the same quota-based convenience sampling in the context of a research methodology course. 81 students participating to this course were asked to recruit 6 participants each (3 males and 3 females, aged over 18), leading to 486 completed questionnaires. The process of spreading was similar to the first study. Participants in Study 1 did not take part in Study 2. 
Two factors were manipulated as follows. Factor 1: presence vs. absence of scent (similar manipulation as in Study 1); Factor 2: presence of a pictorial stimulus vs. presence of a mental imagery instruction $v s$. absence of a secondary stimulus. The pictorial stimulus was a photograph of an electric toothbrush (see Appendix 3). The mental imagery instruction is an instruction encouraging individuals to mentally picture the electric toothbrush involved in the creative exercise. The instruction is displayed below.

Think of an electric toothbrush. Imagine it for a moment, try to picture it mentally (i.e., in your mind). Stare at this image for several seconds. Look carefully at the image that comes to mind: the general appearance of the toothbrush, its contours, color, shape, characteristics, details, etc.

Imagine yourself or another person using this electric toothbrush. From these mental representations, imagine as many innovative ideas as possible that will improve the brushing experience for users.

As in Study 1, perceived personal role $(M=4.3$; $\mathrm{sd}=1.50)$, individual creativity $(\mathrm{M}=4.15$; $\mathrm{sd}=$ 1.55) and gender were included as control variables and measured using 7-points Likert scales. Two questionnaires were excluded for missing data on the individual creativity measure. The final sample resulted in 484 usable questionnaires $\left(49 \%\right.$ male, $\left.M_{\text {Age }}=33.7, \mathrm{sd}=15.63\right)$. A total of 2074 ideas were generated by all respondents $(\min =1, Q 1=3$, median $=4, Q 3=5, \max =20)$. Due to the non-normality of the creative fluency variable, we display the median and $1^{\text {st }}$ and $3^{\text {rd }}$ quartiles instead of the mean and standard deviation. The repartition of respondents between the 6 experimental cells is shown below in Table 2 .

Table 2 - Distribution of subjects between experimental conditions (Study 2)

\begin{tabular}{|c|c|c|c|}
\hline & & \multicolumn{2}{|c|}{$\begin{array}{l}\text { Diffusion of a congruent scent } \\
\text { (scent similar to fresh mint) }\end{array}$} \\
\hline & & Absence & Presence \\
\hline \multirow[t]{3}{*}{ Secondary Stimulus } & Absence & 95 & 75 \\
\hline & Presence of a pictorial stimulus & 60 & 90 \\
\hline & Presence of mental imagery instruction & 89 & 75 \\
\hline
\end{tabular}

\section{Analysis and results}


Due to the non-normality of the creative fluidity measure, the same rank transformation as in Study 1 was applied. The results were also analyzed using an ANCOVA. We display in Table 3 the effect size coefficient (partial eta-squared) and its p-value. In Figure 2, we display the rank transformed estimated marginal means of number of ideas generated.

Table 3 - ANCOVA results on the number of ideas generated (Study 2)

\begin{tabular}{|l|c|c|}
\hline \multicolumn{1}{|c|}{ Variable } & $\begin{array}{c}\text { Partial eta- } \\
\text { squared }\end{array}$ & p \\
\hline Scent diffusion vs. absence of scent & $0.006^{*}$ & 0.092 \\
\hline $\begin{array}{l}\text { Pictorial stimulus vs. mental imagery instruction vs. absence of secondary } \\
\text { stimulus }\end{array}$ & $0.001 \mathrm{ns.}$ & 0.888 \\
\hline Interaction Scent x Secondary Stimulus & $0.013^{* *}$ & 0.043 \\
\hline Individual creativity & $0.009^{* *}$ & 0.039 \\
\hline Perceived Role & $0.001 \mathrm{~ns}$. & 0.537 \\
\hline Gender & $0.006 \mathrm{~ns}$. & 0.104 \\
\hline
\end{tabular}

$* * * \mathrm{p}<0.01, * * \mathrm{p}<0.05, * \mathrm{p}<0.1, \mathrm{~ns}$. Non-significant 
Figure 2 - Estimated Marginal Means of Creative Fluidity (Rank Transformed) (Study 2)

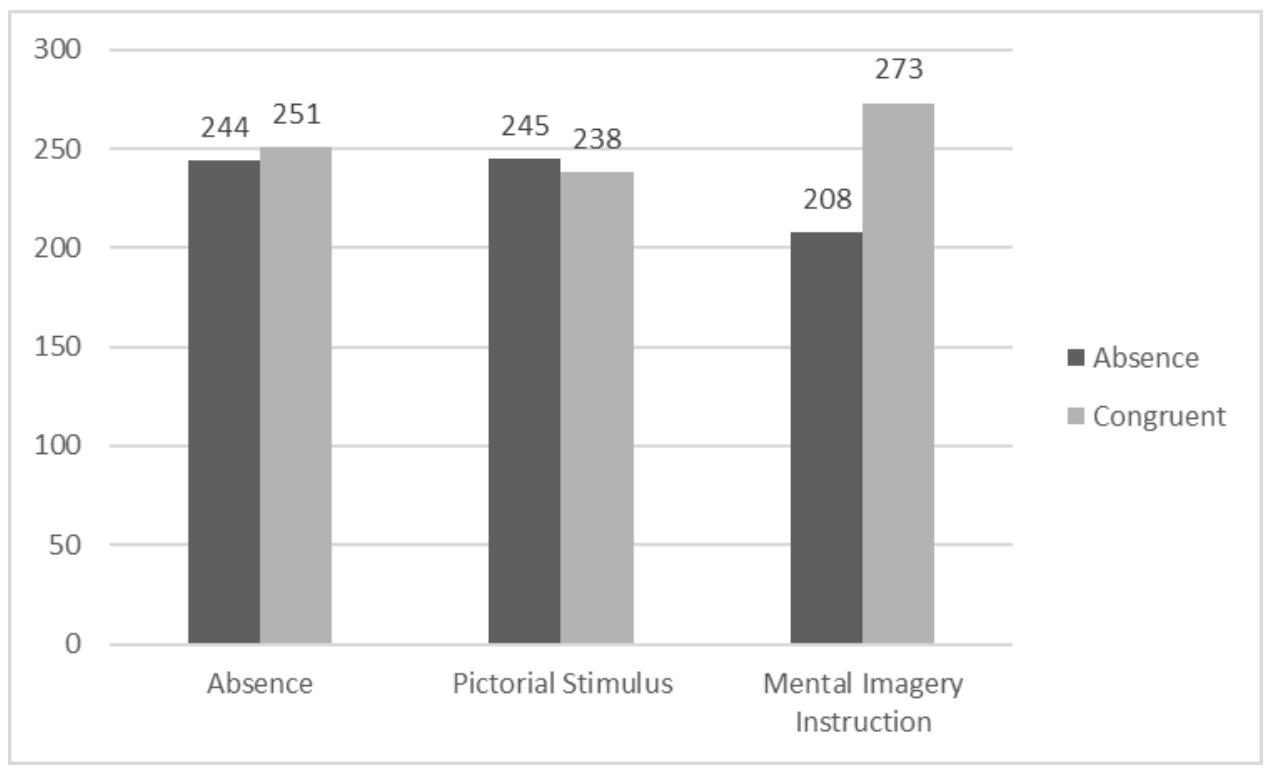

The results again show a weakly significant direct effect of olfactory stimulation on creative fluidity $\left(\right.$ MRank $_{\text {Absence }}=233$, MRank $\left._{\text {Congruent }}=254, \mathrm{p}=0.092\right)$. More interestingly, the interaction between olfactory stimulation and secondary stimulation is significant $(\mathrm{p}=0.043)$. The study of the marginal means reveals an overperformance of the condition "Congruent Scent x Mental Imagery Instruction" (MRank $=273$ ). The conjunction of two sensory stimulations (MRank $=238$ ) does not seem to outperform either the olfactory stimulation alone (MRank $=251)$ or the visual stimulation alone (MRank $=245$ ). In terms of absolute numbers of ideas generated, the experimental condition "Congruent Scent x Mental Imagery Instruction" leads to a mean of around 4.8 ideas per participant, while the conditions "Congruent Scent alone", "Pictorial Stimulus Alone", "Congruent Scent x Pictorial Stimulus" and "No Stimulus" lead to a mean of around 4.2 ideas per participant.

Our results support $\mathrm{H} 3 \mathrm{a}$, showing that the conjunction between the diffusion of a congruent scent and a mental imagery instruction lead to the highest level of creative fluidity. $\mathrm{H} 3 \mathrm{~b}$, on the other hand, is not supported by our results. We find that the conjunction of two sensorial stimuli (olfactory and visual) do no lead to higher levels of creative fluidity than one sensorial stimulus alone. We also find support for a direct effect of olfactory stimulation alone, with a weaker effect than in Study 1.

\section{Discussion}

This research illustrates two main findings: the potential of the diffusion of a congruent scent in terms of stimulating the creative fluidity of the subjects and the potential of using several types of stimuli together in order to maximize the creative fluidity of individuals. These results contribute to the literature on co-creation by highlighting the potential of olfactory stimuli in improving the creative performance of individuals. Olfactory stimuli have a more direct effect on cognitive mechanisms because they are less controlled by reason (Maille, 2001), undoubtedly allowing a freer stimulation of individual creativity. Our results show an effect of olfactory stimulation on 
creative fluidity, as well as an increase in this effect when this stimulation is coupled with mental imagery instruction. It is conceivable that the process of mental imagery activated by olfactory stimulation could be of a different, albeit complementary, nature to that induced by the mental imagery instruction: olfactory stimulation induce more diverse and less product-related images, and the mental imagery instruction refocus these "free associations" around the product, thus enabling the respondent to produce more ideas. On the other hand, previous research has highlighted the power of scents to improve attention related to a task (Vilaplana and Yamanaka, 2015). The use of scents could thus improve people's concentration abilities, and improve the efficiency of the mental imagery instruction. Further research is needed to better understand these combination effects.

These results also support, at least partially, previous results that support an influence of the senses on the cognitive capacities of individuals (Embodied Cognition, Krishna et al., 2017). On the other hand, it should also be noted that only two senses were stimulated (sight and olfaction), but the 5 senses must be understood in a global way because the perception of individuals is holistic and interaction effects could be highlighted if several senses were stimulated. As the Gestalt theory states, "the sum of the whole is greater than the sum of its component parts" (Solomon et al. 2010, p.133); people's perceptions are global and other senses stimulated (e.g., touch) could thus produce different results. Our results suggest that the combination of visual and olfactory stimulation does not improve creative fluidity compared to the stimulation of only one of these two senses. Since our combination involves a high degree of congruency between the iconic (toothbrush) and olfactory (fresh mint) stimuli, we postulate that these stimulations could be redundant. Further research could investigate is a less congruent combination of visual and olfactory stimulation leads to similar results.

Other variables may play a role (the level of congruence of the scent with a precise concept) may impact the results obtained differently, for example a pleasant scent that is congruent with the individual's gender will have an impact on the perception of aesthetics (unlike other situations) (Doucé et al., 2016). Thus, the surprising side of new scents could induce more creative thinking compared to scents known to the individual. Nevertheless, to our knowledge, no research has been able to demonstrate a link between a specific family of scents and an impact on creativity.

In terms of managerial recommendations, our results provide practitioners with keys to foster the creative fluidity of the subjects involved in co-creation approaches or to stimulate the creative fluidity of employees. Indeed, the results show that the conjunction of congruent olfactory stimulation with the product concerned by the task and mental imagery instruction increases the number of ideas produced by respondents. These actions are simple to implement by managers, inexpensive and not very time-consuming, which represents an interesting alternative to targeting expert or creative individuals (such as lead users). Even on products or services not directly associated to a specific scent, it is possible to induce some evocations with scents through transfer of semantic association (Krishna, Elder, \& Caldara, 2010). Furthermore, incongruent scents have been found not to hurt perception of products (Bosmans, 2006). Hence, it could be positive for managers to use scent for stimulating creativity even if there is not a "natural" congruence between the project and the scent used during the task. We discuss future research related to this topic below.

Moreover, with the development of telecommuting (due to the Covid-19 crisis) and in a context of digital transformation, companies wishing to pursue the development of new products through co- 
creation could send small perfume capsules to respondents' homes and have them read the mental imaging instructions digitally. The crowdsourcing process would then be unaffected by this type of health crisis.

These results also show that academics could also use sensory stimuli other than the simple visual stimulus to increase the creative fluidity of individuals. Indeed, research already conducted on the stimulation of creativity and the rigid or open orientation of individuals (student population) shows that stimulating them towards more open ideas leads to more positive results than without this stimulation (Riquelme, 2000). The fact of diffusing a perfume could thus help students to be more creative and to better respond to the new needs of the market. Universities and business schools looking for new techniques to stimulate their students' creative fluidity could use these techniques.

This exploratory study has a number of limitations. First, we found no effect of olfactory stimulation on mental imagery processes. A possible explanation is that we studied mental imagery from the perspective of the mental imagery formation simplicity. It would be interesting to measure this process from the perspective of its other dimensions (like the quantity or valence of the mental images produced). We expect future research to challenge our results and link olfactory stimulation and mental imagery processes, as indicated by the literature (Gavard-Perret and Helme-Guizon, 2003).

Second, while we focus here on creative fluidity as output, the ideas generated could also be evaluated according to qualitative criteria (originality, usefulness, attractiveness of the ideas). Similarly, a creative task orientation could be measured because proposing ideas as part of one's work, in an ideas competition, or solving a personal problem may not generate the same involvement.

Finally, these results open up several other research avenues. One interesting avenue of research concerns the congruence or noncongruence of the scent. Studies have shown that free creative processes mobilize analogical methods of thinking, i.e., the transfer of information from source domains (sources of inspiration) to the target domain (the creative task). Within this framework, a large distance between source and target domain increases the creativity of individuals when the creative task is structured around an instruction to transfer similarities (Gotteland et al., 2017). For example, the diffusion of a moderately congruent scent may lead to the formation of more distant mental images, thereby having positive effects on creative fluidity. Similarly, other complementary mechanisms, possibly explanatory, should be considered, such as divergent thinking processes (Guildford, 1967), Janusian thinking (Rothenberg, 1979, 1996), bisociation (Koestler, 1964), homospatial thinking (Rothenberg, 1979), emotional resonance (Lubart \& Getz, 1997), and analogical transfert (Finke, Ward \& Smith, 1992). They require further investigation to determine which treatment variables and/or processes they involve. These suggestions merit further investigation in future research.

[1] Mental imagery instructions refer to external prompts that direct the subject to construct a pictorial representation from verbal data.

[2] Iconic or pictorial stimuli refer to any objective visual material, such as pictures, drawings, illustrations, and photographs. 
[3] The literature identifies seven dimensions that qualify the process and output of imagery: vividness, clarity, quantity, ease of formation, valence, degree of elaboration and connection to self.

\section{References}

Amabile, T. M. (1983). The social psychology of creativity: A componential conceptualization. Journal of personality and social psychology. 45, 2, 357-376.

Ardelet-Massieu, C. (2011). Do ambient scents always make places and products more attractive? The role of mental imagery. PhD thesis. University Paris Dauphine.

Ardelet-Massieu, C., Briand-Decre, G., \& Zoghaib, A. (2010). Need for stimulation? The role of symbolic association in evaluating the environment. Research paper. Dauphine University research center.

Arshamian, A., \& Larsson, M. (2014). Same same but different: The case of olfactory imagery. Frontieres in Psychology, 5, 1-8.

Baer, J., \& Kaufman, J.C., (2008), Gender differences in creativity, The Journal of Creative Behavior, 42, 2, 75-105.

Baron, R.A., \& Thomley, J. (1994). A whiff of reality : positive affect as a potential mediator of the effects of pleasant fragrances on task performance and helping. Environment and Behavior, 26, 766-784.

Basadur, M., Graen, G.B., \& Green, S.G. (1982). Training in creative problem solving: Effects on ideation and problem finding and solving in an industrial research organization. Organizational Behavior and Human Performance, 30, 41-70.

Berthon, P.R., Pitt, L.F., McCarthy, I., \& Kates, S.M. (2007). When customers get clever: managerial approaches to dealing with creative consumers. Business Horizons, 50, 39-47.

Bone, P. \& Ellen, P. (1990). The effect of imagery processing and imagery content on behavioral intentions. Advances in Consumer Research, 17,1, 449-454.

Bone, P. \& Ellen, P. (1992). The generation and consequences of communication-evoked imagery. Journal of Consumer Research, 19,1, 93-104.

Bonnin, G., \& Goudey, A. (2013). Can sensory stimulation decrease rumination? An exploration of the influence of senses on repeated mental simulation. In NA - Advances in Consumer Research, eds. Botti, S., \& Labroo, A., Duluth, MN : Association for Consumer Research, 41, 533-534.

Borgianni, Y., Maccioni, L., Fiorineschi, L. and Rotini, F. (2020). Forms of stimuli and their effects on idea generation in terms of creativity metrics and non-obviousness, International Journal of Design Creativity and Innovation, 8,3, 147-164.

Bosmans, A. (2006). Scents and Sensibility: When Do (In)Congruent Ambient Scents Influence Product Evaluations? Journal of Marketing, 70,3, 32-43.

Brun, J., Le Masson, P. and Weil, B. (2019). Out of the picture ? How incompatible knowledge and distant visual stimuli may foster idea generation, Creativity and Innovation Management, 28, 368-388.

Burroughs, J.E., Dahl, D.W., Page Moreau, C., Chattopadhyay, A., Gorn, G. J. (2011). Facilitating and rewarding creativity during new product development. Journal of Marketing, 75, 53-67.

Conover, W. J. (2012). The rank transformation-an easy and intuitive way to connect many nonparametric methods to their parametric counterparts for seamless teaching introductory statistics courses. Wiley Interdisciplinary Reviews: Computational Statistics, 4, 432-438. 
Cornil, Y., \& Chandon, P., (2016). Pleasure as a substitute for size: How multisensory imagery can make people happier with smaller food portions. Journal of Marketing Research, 53, 847-864.

Dahl, D.W., Chattopadhyay, A., \& Gorn, G.J. (1999). The use of visual mental imagery in new product design. Journal of Marketing Research, 36, 18-28.

Dahl, D.W. \& Hoeffler, S. (2004). Visualizing the self: Exploring the potential benefits and drawbacks for new product evaluation. The Journal of Product Innovation Management, 21, 4, 259-267.

Denis, M. (1982). Représentation imagée et résolution de problèmes. Revue française de pédagogie, 60, 1, 19-29.

Denis, M. (1989). Images et cognition, Paris, Presse Universitaire de France.

Doucé, L., Jenssens W., Leroi-werelds S. and Streukens S., (2016). What to diffuse in a genderspecific store? The effect of male and female perfumes on customer value and behaviour, Journal of Consumer Behaviour, 15, 3, 271-280.

Errajaa, K., Daucé B., and Legohérel P., (2020). Consumer reactions to olfactory congruence with brand image, Journal of Retailing and Consumer Services, 52.

Fernández-Abascal E et Martín Díaz MD (2013) Affective Induction and Creative Thinking.

Creativity Research Journal 25: 213-221.

Finke, R.A. (1985). Theories relating imagery to perception. Psychological Bulletin, 98, 236-59.

Finke, R.A. (1990). Creative imagery: discoveries and inventions in visualizations, Hillsdale. N.J.: Lawrence Erlbaum Associates, Inc.

Finke, R. A., Ward T. B., et Smith S. M. (1992). Creative Cognition: Theory, Research, and Applications, Cambridge, MA: MIT Press.

Forthmann, B., Gerwig, A., Holling, H., Celik, P., Storme, M., Lubart, T. (2016), The be-creative effect in divergent thinking: The interplay of instruction and object frequency. Intelligence, 57 , 25-32.

Gavard-Perret, M.-L., \& Helme-Guizon, A. (2003). L'imagerie mentale : un concept à découvrir ou à (re)découvrir pour ses apports en marketing. Recherche et Applications en Marketing, 18, 59-79.

Gavard-Perret, M.-L., \& Vellera, C. (2017). La présence d'exemples dans les briefs créatifs : source d'amélioration de la production créative, du rôle personnel perçu et du plaisir ?. Congrès International de l'Association Française du Marketing (AFM), Tours, France.

Gordon, W. J. J. (1968). Synectics: The development of creative capacity. New York: Harper and Row.

Gotteland, D., Merle, A., \& Trendel, O. (2017). Stimulating consumers' creativity through analogical thinking: how can transfer distance and transfer content be matched?, Recherche et Applications en Marketing, 33, 73-87.

Gregory, W.L., Cialdini, R.B. \& Carpenter, K.M. (1982). Selfrelevant scenarios as mediators of likelihood estimates and compliance: Does imagining make it so?, Journal of Personality and Social Psychology, 43,1, 89-99.

Guilford JP (1950) Creativity. American Psychologist, American Psychological Association 5(9): 444-454.

Hayes, A.F. (2013). Introduction to mediation, moderation, and conditional process analysis: A regression-based approach. Guilford Press.

Helme-Guizon, A. (1997). Image, imagerie mentale et effets de la communication persuasive : application à une oeuvre d'art incluse dans une annonce publicitaire, $\mathrm{PhD}$ Thesis, DMSP, Université de Paris-Dauphine. 
Herz, R.S., \& Schooler, J.W. (2002). A naturalistic study of autobiographical memories evoked by olfactory and visual cues: testing the proustian hypothesis. American Journal of Psychology, $115,21-32$.

Hoffman, D.L., Kopalle, P.K., \& Novak, T.P. (2010). The "Right" consumers for better concepts: identifying consumers high in emergent nature to develop new product concepts, Journal of Marketing Research, 47, 854-865.

Jaquish, G.A. (1983). Intra-individual variability in divergent thinking in response to audio, visual and tactile stimuli, British Journal of Psychology, 74, 467-472.

Kim, H., \& Krishnan, S. (2013). Yes, "touch" matters: the impact of touch on consumer creativity. In NA - Advances in Consumer Research, eds. Botti S., \& Labroo, A., Duluth, MN : Association for Consumer Research.

Kisielius, J., \& Strenthal, B. (1984). Detecting and explaining vividness effects in attitudinal judgments., Journal of Marketing Research, 21, 54-64.

Knasko, S.C. (1992). Ambiant odor effect on creativity, mood and perceived health, Chemical Senses, 17, 27-35.

Krishna, A., Elder, R. S., \& Caldara, C. (2010). Feminine to smell but masculine to touch? Multisensory congruence and its effect on the aesthetic experience, Journal of Consumer Psychology, 20, 4, 410-418.

Krishna, A., \& Elder, R. (2011). Experiencing the senses: The interplay of sensory perception and cognition. Advances in consumer research, Saint Louis, 61-64.

Krishna, A., Lee, S.W.S., Li, X., \& Schwarz, N. (2017). Embodied Cognition, Sensory Marketing, and the Conceptualization of Consumers' Judgment and Decision Processes: Introduction to the Issue. Journal of the Association for Consumer Research, 2, 377-381.

Iman, R.L., \& Conover, W.J. (1979). The use of the rank transform in regression. Technometrics, 21, 499-509.

Kristensen, T., (2004). The physical context of creativity. Creativity and Innovation Management, 13, 89-96.Le Nagard-Assayag, E., \& Reniou, F. (2013). Co-innover avec les clients : entre intérêt et réticence pour les entreprises grand public. Décisions Marketing, 71, 59-75.

LeBoutillier, N., \& Marks, D.F. (2003). Mental imagery and creativity: A meta-analytic review study. British Journal of Psychology, 94, 29-44.

Lee, S.W.S. (2016). Multimodal Priming of Abstract Constructs, Current Opinion in Psychology, $12,37-44$.

Lee, S.W.S., \& Schwartz, N. (2014). Metaphor in judgment and decision making, The Power of Metaphor: Examining Its Influence on Social Life, ed. Landau, M., Robinson, M.D., \& Meier, B.P.,Washington, DC: American Psychological Association, 85-108.

Leguerer, A. (1988). Les pouvoirs de l'odeur. Françoise Bourin, Paris.

Lenclud, G. (2006). La nature des odeurs. Terrain, 47, 5-18.

Lilien, G., Morrison, P. D., Searls, K., Sonnack, M., \& von Hippel, E. (2002). Performance assessment of the lead user idea-geneçration process for new product development. Management Science, 48, 1042-1059.

Lubart, T. (2003). Psychologie de la créativité. Ed. Armand Colin.

Lubart T. I. et Getz I. (1997). Emotion, metaphor and the creative process, Creativity Research Journal, 10, 285-301.

Lutz, K., \& Lutz, R. (1978). Imagery-eliciting strategies: review and implications of research, in Hunt, K., Advances in Consumer Research, 5, Ann Arbor, MI: Association for Consumer Research, 611-620. 
Madzharov, A. V., Block, L. G., \& Morrin, M. (2015). The cool scent of power: Effects of ambient scent on consumer preferences and choice behavior, Journal of Marketing, 79, 1, 83-96.

Maille, V. (2001). Impact of olfactory stimuli on consumer behavior: a state of art, Recherche et Applications en Marketing, 16, 51-75.

Maille, V., \& Fleck, N. (2011). Congruence perçue par le consommateur: vers une clarification du concept, de sa formation et de sa mesure, Recherche et applications en Marketing, 26, 77-111.

Mattila, A.S., \& Wirtz, J. (2001). Congruency of scent and music as a driver of in-store evaluations and behavior, Journal of Retailing, 77, 273-289.

Miller, D., \& Marks, L.J. (1992). Imagery and sound-effects in radio commercials, Journal of Advertising, 21, 83-93.

Mitchell, D.J., Kahn, B.E., \& Knasko, S.C. (1995). There's something in the air: effects of congruent or incongruent ambient odor on consumer decision making. Journal of Consumer Research, 22, 229-238.

Nallet, P. (1985). Rôle et importance des odeurs dans le comportement de l'homme. Pharmaceutical PhD, University of Poitiers.

Nehmé L., Barbar R., Maric Y. and Jacquot M. (2016), Influence of odor function and color symbolism in odor-color associations: A French-Lebanese-Taiwanese cross-cultural study, Food quality and preference, 49, 33-41.

Nenkov, G.Y., Morrin, M., Maille, V., Rank-Christman, T., \& Lwin, M.O (2019). Sense and sensibility: The impact of visual and auditory sensory input on marketplace Mmorality. Journal of Business Research, 95, 428-441.

Osborn, A. (1963). Applied imagination: Principles and procedure of creative problem solving. New York, Charles Scribner's Sons.

Pagnani, A. R. (2011). Gender differences. In M. A. Runco \& S. R. Pritzker (Eds.), Encyclopedia of creativity (Second Edition) (pp. 551-557). San Diego: Academic. R

Richardson, A. (1969). Mental imagery, London: Routledge \& Kegan Paul.

Rieunier, S., Daucé, B., Dion, D., Gallopel-Morvan, K., Gentric, M., Maille, V., Remy, E., Roullet, B. \& Sikierski, E. (2017). Le marketing sensoriel du point de vente ( $5^{\text {th }}$ ed.). Paris, Dunod.

Riquelme, H. (2000). How to develop more creative strategic plans: results from an empirical study. Creativity and Innovation Management, 9, 14-20

Ritter, S.M., Strick, M., Bos, M.V., Van Baaren, R.B., \& Dijksterhuis, A. (2012). Good morning creativity: task reactivation during sleep enhances beneficial effect of sleep on creative performance. Journal of Sleep Research, 21, 643-647.

Ritter, S.M., \& Dijksterhuis, A. (2014). Creativity-the unconscious foundations of the incubation period. Frontiers in Human Neuroscience, 8, 215.

Ritter, S.M. \& Ferguson, S. (2017). Happy creativity: Listening to happy music facilitates divergent thinking. PLoS ONE, 12, 9.

Robinson, S.R., Irmak, C. \& Jayachandran, S. (2012). Choice of Cause in Cause-Related Marketing. Journal of Marketing, 76,4, 126-139.

Rothenberg, A. (1979). The emerging goddess: The creative process in art, science and other. elds. Chicago: University of Chicago Press.

Rothenberg A. (1996). The Janusian process in scientific creativity, Creativity Research Journal, 9, 2-3, 207-231.

Runco, M.A. (1991), Divergent thinking, Westport (CT), Ablex Publishing.

Runco, M.A. \& Acar, S. (2012), Divergent thinking as an indicator of creative potential. Creativity Research Journal, 24, 66-75. 
Runco, M. A., Cramond, B., \& Pagnani, A. R. (2010). Gender and creativity. In J. C. Chrisler \& D. R. McCreary (Eds.), Handbook of gender research in psychology (pp. 343-357). New York: Springer

Scott, G., Leritz, L.E., \& Mumford, M.D. (2004a). The effectiveness of creativity training: a quantitative review, Creativity Research Journal, 16, 361-388.

Scott, G., Leritz, L.E. \& Mumford, M.D. (2004b). Types of creativity training: approaches and their effectiveness, Journal of Creative Behavior, 38, 149-179.

Shepard, R.N. (1978). Externalization of mental images and the act of creation. In Randhawa, B.S., \& Coffman, W.E. (Eds.), Visual learning, thinking and communication (133-189), New York:Academic Press.

Solomon, M.R., Bamossy, G., Askegaard, S., \& Hogg, M.K. (2010). Consumer behavior, a European perspective (4th ed.). Prentice hall, Financial Times.

Spence, C. (2018). Multisensory perception, sensation, perception and attention. In Stevens' Handbook of Experimental Psychology and Cognitive Neuroscience (4th ed.).

Torrance, E.P. (1976), Tests de pensée créative, Paris, Editions du Centre de Psychologie Appliquée.

Vellera, C., \& Gavard-Perret, M.-L., (2016a). A better understanding of the role and underlying mechanism of stimulating mental imagery in improving the creativity of "ordinary" users, Recherche et Applications en Marketing, 31, 122-143.

Vellera, C., \& Gavard-Perret, M.-L., (2016b). Repérer les consommateurs créatifs par leur capacité d'imagerie mentale ?, Décisions Marketing, 82, 17-32.

Vilaplana, A., Yamanaka, T., (2015). Effect of smell in space perception, International Journal of Affective Engineering, 14 (3), 175-182.

Wang, C., Mehta, R., Zhu, R., \& Argo, J. (2019). Dim or bright? The impact of ambient illuminance on consumer response to innovative solutions, Journal of the Association for Consumer Research, 4, 293-303.

Zhu, R., \& Mehta, R. (2017). Sensory Experiences and Consumer Creativity, Journal of the Association for Consumer Research, Online First.

\section{Appendix 1: Creative task}

Electric toothbrushes, a product of our daily lives, have been very popular in recent years. Although there are many brands on the market, electric toothbrushes look similar and seem to offer the same advantages. It is often difficult for consumers to make a choice. We want to reinvent electric toothbrushes to make them more attractive.

Find innovative ideas to completely rethink and boost the electric toothbrush offering by proposing something consumers have never seen before that will completely revolutionize their tooth brushing experience.

Your ideas must be original and may relate to the design of the electric toothbrush (appearance, materials), the functionalities and technologies incorporated in the electric toothbrush, its ergonomics, etc. or any other subject you might think of.

\section{Appendix 2 - Measurement instruments}

\section{Creative fluidity}


Write down on the following pages all the innovative ideas that can improve the brushing experience for the consumers that come to mind and number them.

All the following scales are measured using a 7-points Likert Scale

\section{Perceived Role}

When you read the creative brief, did you feel that you were going to be able to add value with your creative proposals?

When you read the creative brief, did you feel that you were going to be able to help a potential company concerned by your creative proposals?

When you read the creative brief, did you feel that you were going to be able to make a personal contribution with your creative proposals?

\section{Individual creativity}

I consider myself a creative person

Others see me as a creative person

I have many creative activities (drawing, painting, music composition, creative hobbies, etc.)

\section{Mental imagery formation simplicity}

While searching for creative ideas, would you say that mental images (visual, auditory, tactile, olfactory, taste, sensorimotor and organic sensations) came to mind immediately?

While searching for creative ideas, would you say that mental images (visual, auditory, tactile, olfactory, taste, sensorimotor and organic sensations) came to mind with difficulty? (reversed)

\section{Appendix 3 - Pictorial stimulus (Study 2)}

